\title{
A Matrix of the Functions and Organizations that Ensure Continued Healthcare Services in a Disaster
}

DOI: 10.12776/QIP.V20I2.747

\author{
Chisato Kajihara, Masahiko Munechika, Masaaki Kaneko, \\ Masataka Sano, Haizhe Jin
}

Received 27 June 2016, Revised 07 July 2016, Accepted 16 September 2016

\begin{abstract}
Purpose: Japan is one of the most natural disaster-prone countries in the world. In the case of a natural disaster or mass casualty incident, a large number of injured people are likely to go to hospitals, which need to provide more services at such times. Thus, it is necessary for various bodies - such as hospitals, municipalities, medical associations, pharmaceutical associations, and trade associations - to collaborate. For example, coordination among multiple hospitals is important when transporting patients to another hospital if they cannot be examined at the first one.
\end{abstract}

There is a pressing need to establish an Area Disaster Resilience Management System for Healthcare (ADRMS-H) to increase medical resilience. In order to develop an ADRMS-H and ensure that continuous healthcare is provided during calamities, it is necessary to clarify the functions (which we have already explained) and coordination that organizations must perform. Since medical care needs change by the hour during disasters, so do the functions that guarantee ongoing healthcare. This study aims to create a matrix of functions ensuring continued healthcare services in a disaster and relevant organizations to understand each one's role and how they relate to each other.

Methodology/Approach: We used the case of Kawaguchi city in Saitama Prefecture, Japan as an example to illustrate related organizations needed to fulfill the functions for ensuring continued healthcare services. Next, we created a matrix of the functions and organizations.

Findings: This study identified related organizations such as municipalities, hospitals, medical associations, and trade associations in Kawaguchi city. Since functions for ensuring ongoing healthcare change by the hour, so do the organizations, whose transformations we analyzed by the hour. 
Originality/Value of paper: The results of this paper can help people understand how related organizations work together during disasters; in light of this, it will be possible to develop a model for an ADRMS-H in terms of coordination among organizations.

Category: Research paper

Keywords: Disaster medicine; Resilience; Area Disaster Resilience Management System for Healthcare (ADRMS-H); Coordination; Area

\section{INTRODUCTION}

Japan is one of the most natural disaster-prone countries in the world and is especially vulnerable to large earthquakes. The continuation and restoration of business is very important in such circumstances. In particular, the inability to provide healthcare services has a severe impact on disaster areas. Many injured persons are likely to come to hospitals during natural disasters or mass casualty incidents, requiring the hospitals to provide increased healthcare services. Therefore, a medical care system must be established that can provide continuous healthcare services in a disaster.

Business Continuity Planning (BCP) aims to ensure business continuity in the face of disaster risk (ISO, 2012; Japan Institute for Promotion of Digital Economy and Community, 2013; Japanese Standards Association, 2013). Business continuity management systems (BCMSs) are increasingly being implemented to maintain, perform, and improve BCP (ISO, 2012; Japan Institute for Promotion of Digital Economy and Community, 2013; Japanese Standards Association, 2013).

During natural disasters or mass casualty incidents, hospitals must continue to provide not only healthcare services to the regular inpatients and outpatients but also medical treatment to many injured. Thus, hospitals must balance general medical treatment with disaster medicine, a burden other businesses do not have. Furthermore, medical care needs in a disaster change by the hour.

Creating a $\mathrm{BCP}$ in a single organization is not enough to deal with the needs in a disaster and ensure the provision of healthcare services. Disaster medicine requires the coordination of more than one hospital, as well as the municipality, medical associations, pharmaceutical associations, trade associations, and other agencies. Healthcare services cannot be provided efficiently without the cooperation of many organizations. Two examples illustrate how coordination ensures continued healthcare services:

- Coordination between multiple hospitals is important when transporting patients to another hospital if they cannot be examined at the first. 
- Inaccessible roads during a disaster make it difficult to supply medical devices and medication. Therefore, coordination between hospitals and the suppliers of pharmaceuticals and medical devices is necessary.

In order to continue the provision of healthcare services with the cooperation of many organizations, there is a pressing need to establish an Area Disaster Resilience Management System for Healthcare (ADRMS-H) to increase medical resilience.

Organizations' functions and coordination must be clarified to develop an ADRMS-H and ensure the continuity of healthcare during calamities. Since medical care needs change by the hour during disasters, so do the functions that guarantee ongoing healthcare. This study creates a matrix of the functions and organizations that ensure continued healthcare services in a disaster to understand their roles and how they relate to each other. We use the case of Kawaguchi city, Saitama prefecture, Japan, as an example.

\section{PREVIOUS STUDIES}

\subsection{Business Continuity Plans (BCP) and Business Continuity Management System (BCMS)}

$\mathrm{BCP}$ is a documented procedure that enables an organization to respond to a disruptive incident and deal appropriately with the resumption and recovery of its activities. BCP includes procedures related to establishing refuges, rescuing injured persons, establishing rescue procedures, collecting information, and so on. Risks covered by the BCP include natural disasters, pandemics, computer viruses, and similar crises. A BCP is a documented procedure that enables the resumption and recovery of activities in the event of any of the aforementioned risks.

There is no guarantee that frequent improvements will result in an ideal BCP. Dynamic social, economic, and business environments, as well as the probability that a natural disaster will occur, change over time; thus, the importance of establishing a BCMS to maintain, perform, and improve BCP has recently been acknowledged.

Although ISO 22301, which defines BCMS requirements, was published in 2012, it is generic and, as such, is intended to apply to all business types. Thus, it is difficult simply to apply ISO 22301 to healthcare services as well.

Moreover, a BCP and BCMS need to be applied to a single organization. In order to continue the provision of healthcare services, the BCP and BCMS need to be applied in a single area, such as a city. In other words, it will be necessary to establish an ADRMS-H to increase medical resilience. However, an ADRMS-H model has not yet been clarified. 


\subsection{Medical management and support system}

Kajihara et al. (2014) have identified the functions needed to ensure continued healthcare services during the three days immediately after a large earthquake. They have also created both a diagram illustrating the coordination between organizations needed to fulfill the functions and a matrix of those functions and related organizations. However, their discussion is limited to the first three days after an earthquake. The functions required to ensure continued healthcare services change by the hour because the needs of medical care in a disaster change by the hour. Therefore, it is necessary to clarify the functions and matrix for a week or month after an earthquake, based on the changing needs.

Watanabe, et al. (2007) have proposed a medical management and support system for disasters in Shiga prefecture divided into three phases:

- First phase, within three hours after the outbreak of disaster: Emergency medical teams are dispatched to the disaster site in order to collect and report firsthand information in close coordination and cooperation with both ambulance and police personnel.

- Second phase, from three hours to three days after the outbreak of disaster: The emergency medical team triages and treats the injured and then transports seriously injured persons rapidly and systematically to key disaster hospitals.

- Third phase, three days after the outbreak of disaster: Medical and health management along with support systems should be provided for the medical and psychological care of the injured.

The Bureau of Social Welfare and Public Health, Tokyo Metropolitan Government (Bureau of Social Welfare and Public Health, 2015) has divided disaster response into six hourly phases, and both the medical care needs and the medical activities that hospitals should provide in each phase have been clarified.

Thus, Watanabe et al. and the Tokyo Metropolitan Government have divided the phases according to the time elapsed after a disaster, but response times will differ depending on the disaster's scale. 


\section{CLARIFYING THE ROLE OF ORGANIZATIONS IN ENSURING CONTINUOUS HEALTHCARE SERVICES PROVISION DURING A DISASTER}

\subsection{The functions of each phase in ensuring continued healthcare services}

Kajihara, et al. (2015) have analyzed the changes in both healthcare services and medical management and support systems, dividing the phases into four sections to discuss the changes in the functions needed to ensure ongoing healthcare by the hour. The results of these considerations are shown in Table 1.

Table 1 - Changes in both healthcare services and medical management and support systems

\begin{tabular}{|c|c|c|c|c|}
\hline & Phase 1 & Phase 2 & Phase 3 & Phase 4 \\
\hline $\begin{array}{l}\text { Changes in } \\
\text { provided } \\
\text { healthcare } \\
\text { services }\end{array}$ & $\begin{array}{l}\text { - Lifesaving } \\
\text { - First aid at stricken area }\end{array}$ & $\begin{array}{l}\text {-Emergency and critical care } \\
\text { to injured persons } \\
\text { - Transport seriously-injured } \\
\text { persons to non-disaster areas } \\
\text { - Autopsy } \\
\text {-Support for assisted persons } \\
\text { - Patients receiving dialysis } \\
\text { - Ventilated patients, etc. }\end{array}$ & $\begin{array}{l}\cdot \text { Continue to treat the injured } \\
\cdot \text { Continue to provide support } \\
\text { for assisted persons } \\
\cdot \text { Treat for chronic diseases } \\
\text { - Prescribe medicine } \\
\cdot \text { Treat persons with } \\
\text { mental disorders }\end{array}$ & $\begin{array}{l}\text { - Continue to treat persons } \\
\text { with mental disorders } \\
\text { - Receive patients who are } \\
\text { then transported } \\
\text { to other areas }\end{array}$ \\
\hline $\begin{array}{l}\text { Changes in } \\
\text { medical } \\
\text { management } \\
\text { and support } \\
\text { systems }\end{array}$ & \begin{tabular}{|l} 
Hospitals in disaster area) \\
- Deal with treatment \\
using only staff in hospitals \\
(Disaster-stricken area) \\
- Lifesaving with one's fellow \\
residents \\
- Fire fighters and police officers \\
are dispatched to the disaster \\
site for lifesaving purposes
\end{tabular} & \begin{tabular}{|l|} 
- Receive resources \\
from non-stricken area \\
- Disaster Medical \\
Assistance Team (DMAT) \\
- Medicine \\
- Equipment \\
- Request to accept emergency \\
patients
\end{tabular} & $\begin{array}{l}\text { - Request for support from } \\
\text { Red Cross and neighboring } \\
\text { clinics } \\
\text { - DMAT withdraws from } \\
\text { disaster stricken area }\end{array}$ & $\begin{array}{l}- \text { Red Cross withdraws } \\
\text { from disaster stricken area } \\
\text { - Suppliers are restored }\end{array}$ \\
\hline
\end{tabular}

Next, Kajihara, et al. (2015) considered the functions organizations must perform in each phase to ensure continued healthcare services in a disaster within the limits of the medical management and support system shown in Table 1. They referred to several records of and guidelines based on the Great East Japan Earthquake. The functions of phases 2 and 3 are shown in Figures 1 and 2 as an example.

A detailed explanation of Figure 1 will serve as an example. In Figure 1, the arrows indicate the relocation of patients, dead bodies, and medical staff. The required functions are shown from (1) to (8). Triage-determining the priority of treatment depending on the severity of a patient's condition-is very important; seriously injured patients need to be transported quickly to key disaster hospitals. Functions (1) through (4) are triage, treatment, and transportation. Ensuring continued treatment requires that organizations (5) provide resources, (6) manage the bodies of the deceased, (7) support assisted persons, and (8) inform residents about medical relief. The functions of other phases were similarly identified. 


\subsection{A matrix of the functions and organizations}

Figure 1 shows the functions of phase 2, and Figure 2 shows the functions of phase 3.

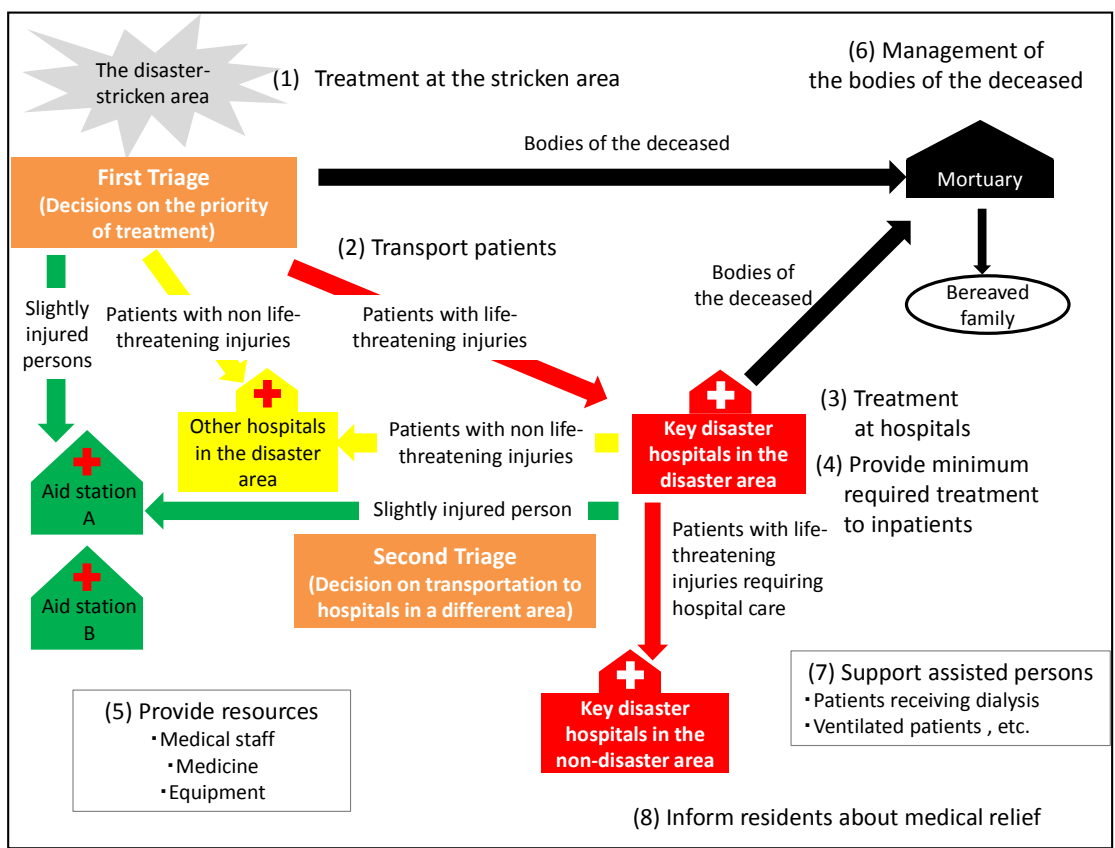

Figure 1-The functions of phase 2

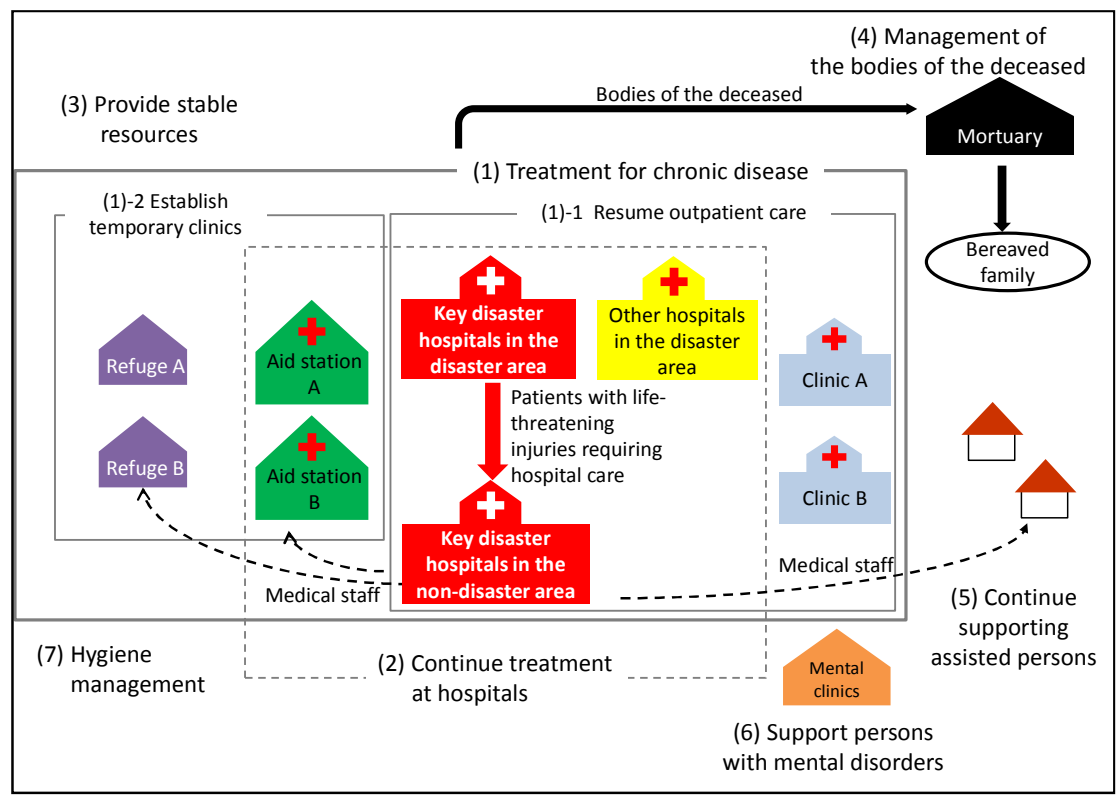

Figure 2 - The functions of phase 3 
However, the functions and coordination have not been clarified in detail, making it difficult to identify the roles of the related organizations. Several investigations were conducted on both the detailed functions and the organizations needed to fulfill them.

First, we investigated the records of the Great East Japan Earthquake to understand what the municipality and hospitals did during the event. Next, we investigated several cities' regional disaster prevention plans, which delineate disaster action plans for municipalities, hospitals, fire brigades, and residents. We investigated the plans of several cities because one city's plan may omit necessary functions. Prefectures and cities in the disaster-stricken area released records on the earthquakes and the regional disaster prevention plans on their websites, which we examined. We identified the roles of each organization (e.g., municipalities, hospitals) using the records and then examined the coordination needed among them to provide effective healthcare services.

We also interviewed two doctors who provided healthcare services at hospitals during the Great East Japan and Great Hanshin/Awaji Earthquakes. We conducted a cooperative study involving 10 hospitals over about 10 years. We asked the doctors of the hospitals to participate in the interview. The interview items included when, where, and how healthcare services were provided during each earthquake.

Through these investigations, we developed the functions shown in Figures 1 and 2 in more detail to clarify them.

We used the case of Kawaguchi city as an example to illustrate how organizations needed to fulfill the functions outlined in Figures 1 and 2. Here, a pivotal key disaster hospital, referred to as Hospital A, provides healthcare services during the disaster. Although Hospital A and the Kawaguchi City office perform important roles, they cannot implement all functions on their own. Therefore, we examined the organizations and traders with whom Hospital A and the Kawaguchi City office concluded agreements for disaster assistance and regarded these organizations and traders as related organizations needed to fulfill various functions.

We then created a matrix outlining the detailed functions and related organizations. The functions performed by each organization were considered by referring to the regional disaster prevention plan of Kawaguchi City, and the correspondence between organizations was included. The regional disaster prevention plan of Kawaguchi city does not include all functions because the organizations in charge of some of the functions have not been decided yet; these functions were left blank in the matrix. The coordination type shown in the matrix is indicated by the marks. These types include a chain of command, a chain of communication between organizations, a chain of demand on other organizations, and a supply of staff and medication. Parts of the matrices of phases 2 and 3 are shown in Tables 2 and 3 as examples. 
【The organization in Charge】@, 【A chain of communication】 $\triangle:$ from, $\mathbf{\Delta}:$ to, 【A chain of demand \O: from,

\begin{tabular}{|c|c|c|c|c|c|c|c|c|c|c|}
\hline \multirow{2}{*}{ Functions } & \multicolumn{2}{|c|}{ Detailed Functions } & \multirow{2}{*}{$\begin{array}{l}\text { Headquarters } \\
\text { Chairman }\end{array}$} & \multirow{2}{*}{$\begin{array}{c}\text { Information } \\
\text { gathering } \\
\text { section }\end{array}$} & \multirow{2}{*}{$\begin{array}{l}\text { Hrre } \\
\text { fighting } \\
\text { section }\end{array}$} & \multirow[t]{2}{*}{$\cdots$} & \multirow{2}{*}{$\begin{array}{c}\text { Hospital } \\
\text { A }\end{array}$} & \multirow{2}{*}{$\begin{array}{c}\text { Hospital } \\
\text { B }\end{array}$} & & \\
\hline & First Hierarchy & Second Hierarchy & & & & & & & & \\
\hline \multirow{7}{*}{\begin{tabular}{|l} 
(1) \\
Treatment \\
at the \\
Disaster \\
Area
\end{tabular}} & \multirow{3}{*}{$\begin{array}{l}\text { (1)-1 Gather the } \\
\text { information on } \\
\text { damages }\end{array}$} & $\begin{array}{l}\text { Grasp the number of injured } \\
\text { persons in target city }\end{array}$ & & (๑) & & & & & & \\
\hline & & $\begin{array}{l}\text { Grasp the situation in relation } \\
\text { to damages } \\
\text { to hospitals and clinics etc. }\end{array}$ & & $\Delta$ & & & $\Delta$ & $\Delta$ & $\Delta$ & \\
\hline & & Grasp the traffic conditions & & & & & & & & \\
\hline & $\ldots$ & $\ldots$ & & & & & & & & \\
\hline & \multirow{3}{*}{$\begin{array}{l}\text { (1)-4 Provide } \\
\text { treatment }\end{array}$} & Implement first triage & & & & & & & & (a) \\
\hline & & Take temporary measures & & & & & & & & (2) \\
\hline & & Confirm amount of dead & & & & & & & & (0) \\
\hline \multirow{5}{*}{\begin{tabular}{|l} 
(2) \\
Treatment \\
at Hospitals
\end{tabular}} & \multirow{2}{*}{\begin{tabular}{|l|} 
(2)-1 Treatment at \\
key disaster \\
hospitals \\
in the disaster area
\end{tabular}} & Implement second triage & & & & & (2) & (2) & & \\
\hline & & $\begin{array}{l}\text { Receive DMAT } \\
\text { (Disaster Medical Assistant } \\
\text { Team) }\end{array}$ & & & & & () & () & & \\
\hline & \multirow{2}{*}{\begin{tabular}{|l} 
(2)-2 Demand \\
admission of \\
patients \\
needing hospital \\
care at other \\
hospitals
\end{tabular}} & $\begin{array}{l}\text { Look for other hospitals to take } \\
\text { patients }\end{array}$ & & & & & & & & \\
\hline & & Demand admission of patients & & & & & & & $\bullet$ & O \\
\hline & $\ldots$ & $\ldots$ & & & & & & & & \\
\hline \multirow{5}{*}{$\begin{array}{l}\text { (3) } \\
\text { Transport } \\
\text { Patients }\end{array}$} & (3)-1 Establish & $\begin{array}{l}\text { Decide places for the } \\
\text { establishment of SCU }\end{array}$ & & & & & & & & \\
\hline & $\begin{array}{l}\text { Stage Care Unit } \\
\text { (SCU) }\end{array}$ & \begin{tabular}{|l} 
Provide resources to SCU \\
Fovaliss SCII
\end{tabular} & & & & & & & & \\
\hline & \multirow{2}{*}{$\begin{array}{l}\text { (3)-2 Secure a } \\
\text { means of }\end{array}$} & \begin{tabular}{|l|} 
Demand ambulances \\
\end{tabular} & $\square$ & & च & & & & & \\
\hline & & \begin{tabular}{|l} 
Demand police cooperation \\
\end{tabular} & 0 & & & & & & & \\
\hline & $\cdots$ & $\ldots$ & & & & & & & & \\
\hline$\cdots$ & $\ldots$ & $\ldots$ & & & & & & & & \\
\hline
\end{tabular}




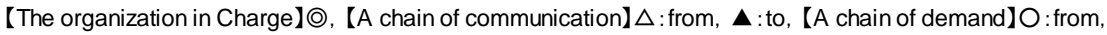

\begin{tabular}{|c|c|c|c|c|c|c|c|c|c|c|c|c|}
\hline & & & & & & & & & & & & \\
\hline & & & \multicolumn{4}{|c|}{ Kawaguchi City Office } & \multicolumn{3}{|c|}{ Hospitals } & \multirow{5}{*}{ DMAT } & \multirow{5}{*}{$\begin{array}{l}\text { The Japan } \\
\text { Dietetic } \\
\text { Association }\end{array}$} & \multirow{4}{*}{$\begin{array}{l}\ldots \\
\ldots \\
\ldots\end{array}$} \\
\hline & & & \multicolumn{3}{|c|}{$\begin{array}{l}\text { In charge of unification and information } \\
\text { gathering }\end{array}$} & \multirow{4}{*}{$\begin{array}{l}\cdots \\
\cdots\end{array}$} & \multirow{2}{*}{\multicolumn{2}{|c|}{$\begin{array}{l}\text { Key disaster } \\
\text { hospitals in } \\
\text { Kawaguchi city }\end{array}$}} & \multirow{4}{*}{\begin{tabular}{|c|} 
Key \\
disaster \\
hospitals \\
in \\
non- \\
disaster \\
areas \\
\end{tabular}} & & & \\
\hline & & & \multirow{3}{*}{$\begin{array}{l}\text { Headquarters } \\
\text { Chairman }\end{array}$} & \multirow{3}{*}{$\begin{array}{c}\text { Information } \\
\text { gathering } \\
\text { section }\end{array}$} & \multirow{3}{*}{$\begin{array}{c}\text { Fire- } \\
\text { fighting } \\
\text { section }\end{array}$} & & & & & & & \\
\hline Functions & Detai & d Functions & & & & & Hospital & Hospital & & & & \\
\hline & First Hierarchy & Second Hierarchy & & & & & & & & & & \\
\hline \multirow{10}{*}{$\begin{array}{l}(1)-1 \text { Resume } \\
\text { outpatient care }\end{array}$} & & Grasp the needs of healthcare & & & & & & & & & & \\
\hline & & Grasp the situation in relation to damages & & & & & & & & & & \\
\hline & (1)-1-1 Gather the information & $\begin{array}{l}\text { Confirm the conditions of electricity, gas, } \\
\text { etc. }\end{array}$ & & & & & & & & & & \\
\hline & & Grasp the conditions of staff & & & & & & & & & & \\
\hline & \multirow{3}{*}{ (1)-1-2 Establish medical system } & \begin{tabular}{|l|} 
Personal distribution \\
\end{tabular} & & & & & () & (-) & & & & \\
\hline & & Provide resources & & & & & $\mathrm{O}$ & $\mathrm{O}$ & & & & \\
\hline & & Establish a system of prescription & & & & & (-) & $\odot$ & & & & \\
\hline & \multirow{3}{*}{ (1)-1-3 Provide medical care } & Examine patients & & & & & (0) & ○ & & & & \\
\hline & & Medical examination & & & & & (๑) & Q & & & & \\
\hline & & Medication & & & & & (ᄋ) & (2) & & & & \\
\hline \multirow{8}{*}{$\begin{array}{l}(1)-2 \text { Establish } \\
\text { temporary clinics }\end{array}$} & \multirow[t]{2}{*}{ (1)-2-1 Establish main aid stations } & $\begin{array}{l}\text { Determine locations of } \\
\text { main aid stations }\end{array}$ & & & & & & & & & & \\
\hline & & Establish aid stations & (2) & & (-) & & & & & & & \\
\hline & \multirow{5}{*}{$\begin{array}{l}\text { (1)-2-2 Provide treatment } \\
\text { at aid stations }\end{array}$} & Manage the disaster relief teams & & & & & & & & & & \\
\hline & & Assess the aid stations and refuge & & & & & & & & & & \\
\hline & & \begin{tabular}{|l|} 
Assign the relief teams \\
\end{tabular} & & & & & & & & & & \\
\hline & & \begin{tabular}{|l|} 
Provide treatment \\
\end{tabular} & & & & & & & & & & \\
\hline & & \begin{tabular}{|l} 
Provide the information to next teams \\
\end{tabular} & & & & & & & & & & \\
\hline & $\cdots$ & & & & & & & & & & & \\
\hline$\ldots$ & $\cdots$ & $\ldots$ & & & & & & & & & & \\
\hline \multirow{3}{*}{\begin{tabular}{|l} 
(6) Support \\
persons with \\
mental disorders
\end{tabular}} & (6)-1 Gather the information & $\begin{array}{l}\text { Grasp the situation in relation to damages } \\
\text { to mental clinics }\end{array}$ & & & & & & & & & & \\
\hline & \multirow{2}{*}{$\begin{array}{l}\text { (6)-2 Establish aid stations for persons } \\
\text { with mental disorders }\end{array}$} & $\begin{array}{l}\text { Determine locations of } \\
\text { aid stations }\end{array}$ & (2) & & & & & & & & & \\
\hline & & Establish aid stations & (ㅇ) & & & & & & & & & \\
\hline \multirow{8}{*}{$\begin{array}{l}\text { (7) Hygiene } \\
\text { management }\end{array}$} & \begin{tabular}{|l|}
$\ldots$ \\
$(7)-1$ Assessment
\end{tabular} & Assess the refuge & & & & & & & & & & \\
\hline & \begin{tabular}{|l|} 
(7)-1 -2 Provide food \\
\end{tabular} & Provide food, water, etc. periodically & & & & & & & & & & \\
\hline & (n)-2 Provide food & Food sanitation & & & & & & & & & (2) & \\
\hline & \multirow{5}{*}{ (7)-3 Solve the problems } & Establish hand-washing facilities & (-) & & & & & & & & & \\
\hline & & Establish provisional toilets & (2) & & & & & & & & & \\
\hline & & Provide masks & (2) & & & & & & & & & \\
\hline & & Nutrition education & Q & & & & & & & & (0) & \\
\hline & & $\ldots$ & & & & & & & & & & \\
\hline
\end{tabular}




\subsection{Using the matrix}

We linked the organizations to detailed functions by referring to Kawaguchi City's regional disaster prevention plan, as shown in Tables 2 and 3. As the plan does not include all functions (as mentioned), organizations will need to be placed in charge of all remaining functions, and the regional disaster prevention plan will need to be revised. The functions without organizations in charge can be identified from the matrix, enabling the revision of the disaster prevention plan and the preparation of procedure manuals.

Table 2 is the matrix of phase 2, and Table 3 is the matrix of phase 3 . Creating the matrix of each phase enables us to grasp the changing roles of each organization by the hour. Disaster-stricken areas are confusing places, and disaster manuals that deal with organizations' changing roles must be available; this will allow hospitals to provide healthcare services effectively and efficiently.

\section{DISCUSSION}

Many injured may arrive at hospitals during natural disasters or mass casualty incidents, which can overwhelm them and deplete medical equipment amid the confusion. Taking immediate action is difficult without an appropriate disaster plan. Negotiating an agreement for coordinating with related organizations and keeping channels of communication open is particularly important. The matrix proposed in this study enable the development of a BCP that considers coordination among organizations, thus facilitating cooperation among them and ensuring the continuity of healthcare services.

During disasters, organizations have little opportunity to communicate because the grounds for discussion are sometimes lacking. This study's matrix is intended to promote communication among related organizations and improve cooperation between hospitals and clinics by clarifying the coordination needed among all of them.

\section{CONCLUSION AND FUTURE ISSUES}

This study has clarified the functions organizations must perform in each phase to ensure continuity in healthcare services during a disaster in detail. We have also clarified the role of each organization using a matrix illustrating the coordination needed among organizations. It is possible to grasp the roles and the coordination of each phase through the matrix.

A future study will develop the ADRMS-H based on the results of this research. 


\section{ACKNOWLEDGMENTS}

I appreciate the constructive advices offered by Kawaguchi city and Kawaguchi Municipal Medical Center.

This research was supported by Research Institute of Science and Technology for Society (RISTEX), Japan Science and Technology Agency (JST). This research was also supported by JSPS KAKENHI Grant Numbers JP16K16360, JP16H01834.

\section{REFERENCES}

Bureau of Social Welfare and Public Health, Tokyo Metropolitan Government, 2015, [online]. Available at http://www.fukushihoken.metro.tokyo.jp/iryo/kyuukyuu/saigai//. [accessed 20 March 2015]

International Standards Office, 2012. ISO 22301:2012 Societal security Business continuity management systems - Requirements. Geneva: ISO.

Japan Institute for Promotion of Digital Economy and Community, 2013. BCMS User's Guide - Corresponding to ISO 22301:2012. Japan Institute for Promotion of Digital Economy and Community, Japan.

Japanese Standards Association, 2013. Societal security -Business continuity management systems- Guidance (A translation printed side by side with the original text), Japanese Standards Association, Japan.

Kajihara, C., Munechika, M., Sano, M. and Kaneko, M., 2014. The functions of related organizations that ensure continuous healthcare services in a disaster for Business Continuity Planning (BCP). Proceedings of 58th EOQ Congress Gothenburg, [CD-ROM].

Kajihara, C., Munechika, M., Kaneko M., Sano M. and Ogawa, K., 2015. The functions of related organizations that ensure continuous healthcare services in a disaster. Proceedings of 5th International Conference on Building Resilience 2015, Newcastle, Australia.

Watanabe, S., Hase, T., Hirose, K., Hukui, M., Yamasiki, Y., Akitomi, S. and Ukai, S., 2007. Development of Medical Management and Support System Against Disaster in Shiga Prefecture. Japanese Journal of Disaster Medicine, 12(1), pp.62-73. 


\section{ABOUT THE AUTHORS}

Chisato Kajihara is an assistant professor of School of Creative Science and Engineering, Waseda University, Tokyo, Japan. She earned Doctor of Management Engineering in 2013. Her research has focused on Quality Management System (QMS) and Business Continuity Management System (BCMS). Waseda University, chisato-k@fuji.waseda.jp, 3-4-1 Okubo Shinjuku Tokyo Japan 169-8555

Masahiko Munechika is a professor in the Department of Industrial and Management System Engineering, School of Creative Science and Engineering, Waseda University since 2007. His research has focused on quality management and statistical analysis, including TQM, sentiment quality, healthcare quality, and management diagnosis. He is also a member of Deming Application Prize Committee and Japanese delegate of ISO/TC176. Waseda University, munechika@waseda.jp, 3-4-1 Okubo Shinjuku Tokyo Japan 169-8555

Masaaki Kaneko is Dr., Junior associate professor, Department of Management Systems Engineering, TOKAI University. Graduated from Waseda University in 2002. His research has focused on total quality management in industry and healthcare field, and BCMS (Business continuity management system). Tokai University, mkaneko@tokai-u.jp, 2-3-23 Takanawa Minato Tokyo Japan 1088619

Masataka Sano is an associate professor at Chiba Institute of technology, Chiba, Japan. He earned a doctoral degree in Engineering in 2011. His research interests are in the areas of patient safety and healthcare quality. Chiba Institute of technology, sano.masataka@p.chibakoudai.jp, 2-17-1 Tsudanuma Narashino Chiba Japan 275-0016

Haizhe Jin is a lecturer in Northeastern University, China. He has big interested in the field of prevention of human-errors, and now, focus on the tool development for it. His research group is cooperation with some medical institutions and the tools developed by them were spread to medical institutions. Northeastern University, hzjin@mail.neu.edu.cn, 3-11, Wenhua Rd., Heping Dist., Shenyang, China 110-819 